\title{
Numerical simulation of liquefaction effects on seismic SSI
}

\author{
Fernando Lopez-Caballero ${ }^{\text {a,* }}$, \\ Arezou Modaressi Farahmand-Razavi ${ }^{\text {a }}$ \\ ${ }^{a}$ Laboratoire MSS-Mat CNRS UMR 8579,Ecole Centrale Paris, Grande Voie des \\ Vignes, 92295 Châtenay-Malabry Cedex, France
}

\begin{abstract}
The present paper deals with the influence of soil non-linearity, introduced by soil liquefaction, on the soil-foundation-structure interaction phenomena. The objective is to reveal the beneficial or unfavourable effects of the non-linear SSI on both structural drift and settlement of a given structure. Factors such as the signal modification due to liquefaction, and ratios of fundamental frequencies of soil, structure and signal may play an important role on the damage of the structure. The importance of each of these factors is evaluated through a significant parametric study. A 2D coupled finite element modelling is carried out using an elastoplastic multimechanism model to represent the soil behaviour. This paper presents the research work we did in the framework of the European Community project NEMISREF (New methods of mitigation of seismic risk on existing foundations, GRDI-40457), to study possible retrofitting measures using GEFDYN computational tools.
\end{abstract}

Key words: Constitutive model, Elastoplastic, Liquefaction, SSI

\section{Introduction}

Traditionally, in the earthquake engineering practice the soil foundation structure interaction phenomenon is studied with the assumption of the linear elastic behaviour for the soil. It is also well known that the seismic response of a structure can be significantly altered by the flexibility of its soil foundation.

\footnotetext{
* Corresponding author.

Email addresses: fernando.lopez-caballero@ecp.fr (Fernando Lopez-Caballero), arezou.modaressi@ecp.fr (Arezou Modaressi Farahmand-Razavi).
} 
In the case where an elastic soil behaviour is assumed, the surface motion will be amplified proportionally to the input motion. However, in reality the amplitude and frequency content of the response are modified due to the soil's stiffness degradation and higher energy dissipation. Therefore, the quantification of local site effects on the input ground motion is of particular importance for earthquake resistant design as well as for the evaluation of seismic damage risk of existing structures.

In this paper, the influence of soil non-linearity, introduced by soil liquefaction, on the soil-foundation-structure interaction phenomena is evaluated. Several single-degree-of-freedom $(S D O F)$ structures founded on a rigid shallow foundation are chosen to reveal, with great simplicity, the beneficial or unfavourable effects of the soil-structure interaction phenomenon. Thus a 2D coupled finite element modelling with GEFDYN [1,2] is carried out using an elastoplastic multi-mechanism model to represent the soil behaviour.

In the first part of this paper, the obtained free field responses of a site using numerical simulation of the underneath soil profile are presented. These simulations are performed in order to evaluate the possibility that liquefaction phenomena may appear. Moreover, the modification of characteristics of surface motion (i.e. acceleration and frequency content) due to apparition of liquefaction are studied.

Furthermore, the response of a soil-structure systems on liquefiable soil is evaluated. The aim of this part is to better understand both the effect of nonlinear soil behaviour on the structure response and the modification of the free field soil response due to the presence of the structure.

The role of several parameters on both the seismic ground acceleration at the structural base and the settlement of the foundation, as well as, the structural drift of SDOF structures are extensively studied. This parametric study concerns the mechanical properties of the structure (mass and frequency) as well as the characteristics of the input motion (i.e. amplitude, frequency content, Arias intensity [3]).

The simulations show that as far as it concerns the effect of soil liquefaction on the soil-structure interaction response, only for some ratios of fundamental frequencies of soil and the structure a significant modification from the elastic condition appears. 


\section{Description of the model}

The FE model is composed of three parts: the soil foundation, a shallow concrete foundation and a single-degree-of freedom (SDOF) structure. The studied site is composed principally of clay layers overlaid by $22 \mathrm{~m}$ of loose sand (i.e. a relative density $D_{r}<50 \%$ ). Figure 1 shows the mesh of the proposed numerical model based on the site measurement of $S P T_{N 60}$ and shear wave velocities $(V s)$ given in figure 2 .

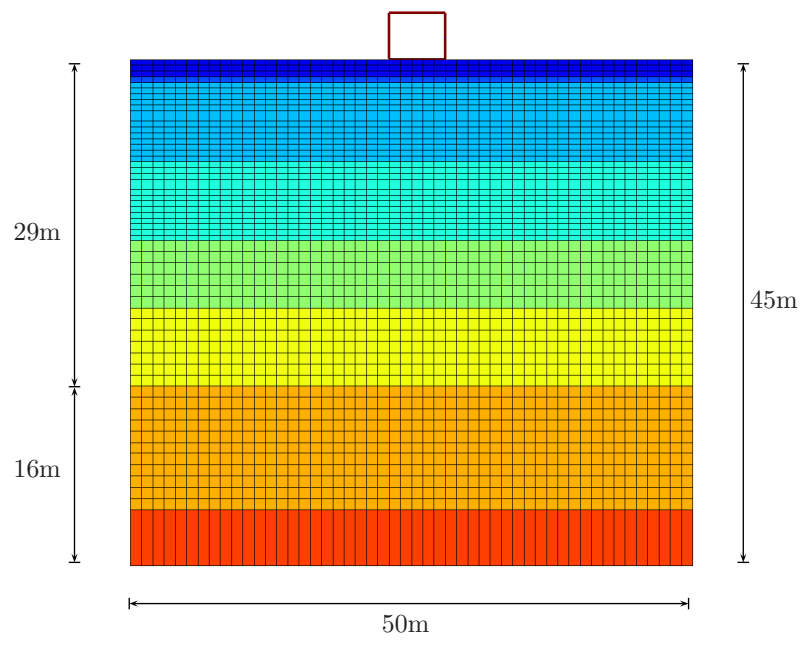

Fig. 1. Proposed finite element model mesh.
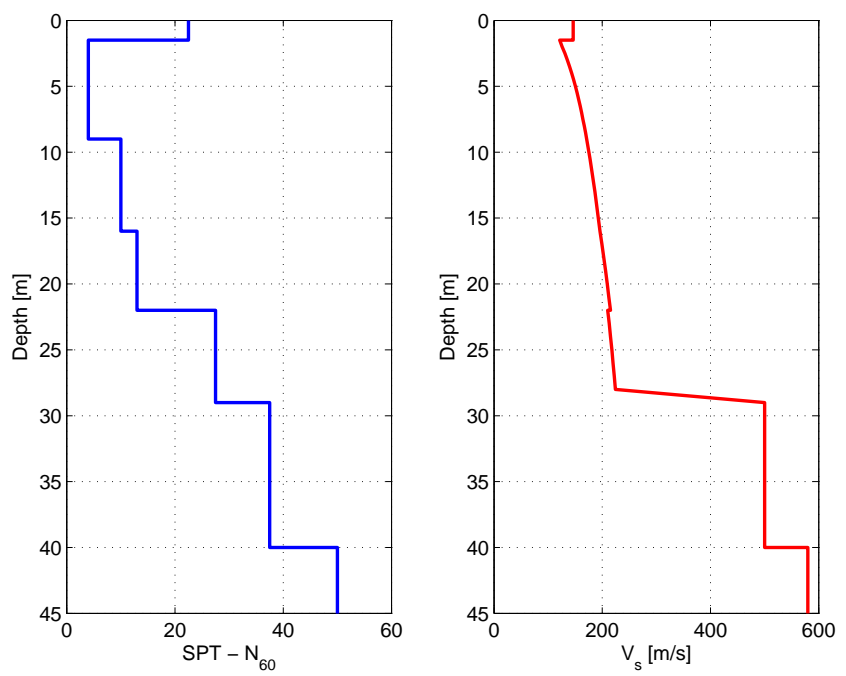

Fig. 2. SPT and S velocity profiles of the site and adopted in the numerical analysis.

According to the SPT test results and the soil description, it is deduced that the liquefaction phenomena can appear at layers between $4 \mathrm{~m}$ and $15 \mathrm{~m}$ depth (SPT $-N_{60}$ between 4 and 10) as from $22 \mathrm{~m}$ depth the soil is composed principally of overconsolidated clay. Thus, an elastoplastic model is only used to represent the soil behaviour on the top $29 \mathrm{~m}$. In these layers, the shear modulus 
of the soil increases with depth. The initial modulus $\left(G_{\max }\right)$ is computed by the following relationship :

$$
G_{\max }=290\left(\frac{\sigma_{\text {mo }}^{\prime}}{p_{\text {ref }}}\right)^{0.5} \quad[\mathrm{MPa}]
$$

Where $\sigma_{m o}^{\prime}$ is the mean effective pressure and $p_{\text {ref }}$ is the pressure of reference (1MPa). For the soil between $29 \mathrm{~m}$ and $40 \mathrm{~m}$, an isotropic linear elastic soil behaviour is assumed. The deformable bedrock is placed at $40 \mathrm{~m}$ depth.

In order to simulate the $S D O F$ structure a frame composed of isotropic elastic beam elements is used. The characteristics of three SDOF structures used in this study, with different frequencies but with the same mass, are summarized in Table 1.

Table 1

Characteristics of single-degree-of freedom structures

\begin{tabular}{c|ccc} 
& $f_{\text {str }}(H z)$ & Mass $M[$ Ton $]$ & height $h[m]$ \\
\hline SDOF 1 & 2.16 & 21 & 4 \\
SDOF 2 & 2.93 & 21 & 4 \\
SDOF 3 & 3.71 & 21 & 4
\end{tabular}

\subsection{Boundary conditions}

In the analysis, where only vertically incident shear waves are introduced into the domain and as the lateral limits of the problem are considered to be far enough, their response is assumed to be the response of a free field. Thus, equivalent boundaries have been imposed on the nodes of these boundaries (i.e. the normal stress on these boundaries remains constant and the displacements of nodes at the same depth in two opposite lateral boundaries are the same in all directions).

For the bedrock's boundary condition, paraxial elements simulating a "deformable unbounded bedrock" have been used [4,5]. The incident waves, defined at the outcropping bedrock are introduced into the base of the model after deconvolution. Thus, the obtained movement at the bedrock is composed of the incident waves and the reflected signal.

The bedrock is supposed to be impervious and the water level is placed at the ground surface. 


\subsection{Input earthquake motion}

The used seismic input motions are the acceleration records for Friuli earthquake - San-Rocco site (Italy-1976), Superstition Hills earthquake - Supers. Mountain site (USA-1987), Kozani earthquake (Greece - 1995) and Aigion earthquake (Greece - 1995). The mean period $\left(T_{m}\right)$ [6] of the four signals varies between 0.28 and $0.56 \mathrm{~s}$ (Figure 3 ). All signals are consistent with the response spectra of Type A soil of Eurocode8.

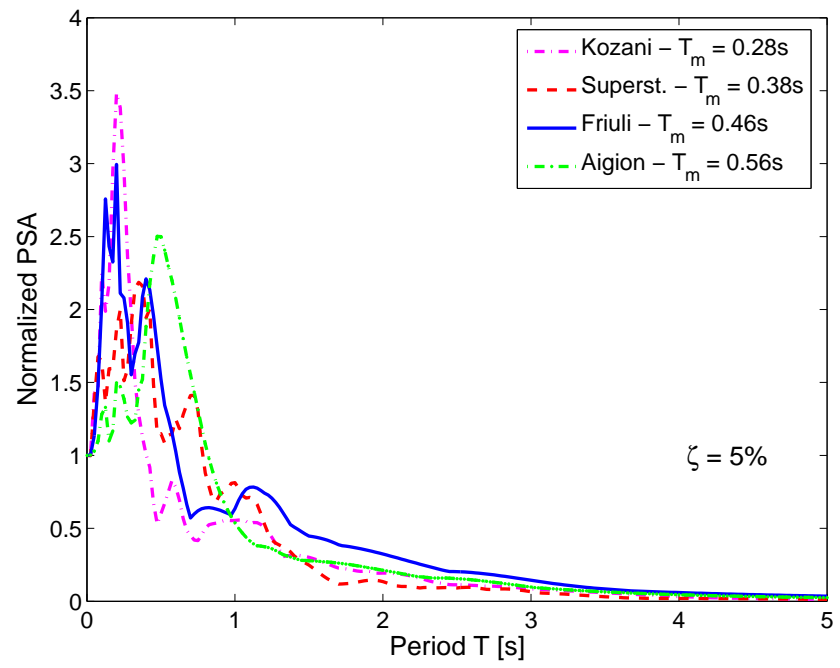

Fig. 3. Normalized acceleration response spectra of used input earthquake motions.

\section{Elastoplastic model}

The ECP's elastoplastic multi-mechanism model [7,8], commonly called Hujeux model is used to represent the soil behaviour. This model can take into account the soil behaviour in a large range of deformations. The model is written in terms of effective stress. The representation of all irreversible phenomena is made by four coupled elementary plastic mechanisms : three plane-strain deviatoric plastic deformation mechanisms in three orthogonal planes and an isotropic one. The projection of any tensors $(\underline{\underline{t}})$ on the deviatoric plane $(k)$ including $\underline{e}_{i}$ and $\underline{e}_{j}$ axes concerns only the $t_{i i}, t_{j j}$ and $t_{i j}$ components, such that, we can write the corresponding mean and deviatoric values of strain and stress tensors as:

$$
\begin{aligned}
& p_{k}^{\prime}=\frac{\sigma_{i i}^{\prime}+\sigma_{j j}^{\prime}}{2} \\
& q_{k}=\left[\left(\frac{\sigma_{i i}^{\prime}-\sigma_{j j}^{\prime}}{2}\right)^{2}+\sigma_{i j}^{\prime 2}\right]^{\frac{1}{2}}
\end{aligned}
$$




$$
\begin{aligned}
\varepsilon_{v k} & =\varepsilon_{i i}+\varepsilon_{j j} \\
\bar{\varepsilon}_{k} & =\left[\left(\frac{\varepsilon_{i i}-\varepsilon_{j j}}{2}\right)^{2}+\varepsilon_{i j}^{2}\right]^{\frac{1}{2}}
\end{aligned}
$$

The model uses a Coulomb type failure criterion and the critical state concept. The evolution of hardening is based on the plastic strain (deviatoric and volumetric strain for the deviatoric mechanisms and volumetric strain for the isotropic one). To take into account the cyclic behaviour a kinematical hardening based on the state variables at the last load reversal is used.

The model is written in the framework of the incremental plasticity, which assumes the decomposition of the total strain increment in two, elastic and plastic, parts. In what follows, a brief overview of the essential aspects of the constitutive model for primary loading paths is given.

The elastic part is supposed to obey a non-linear elasticity behaviour, where the bulk $(K)$ and the shear $(G)$ moduli are functions of the mean effective stress $\left(p^{\prime}\right)$ :

$$
K=K_{\text {ref }}\left(\frac{p^{\prime}}{p_{\text {ref }}}\right)^{n_{e}} \text { and } G=G_{r e f}\left(\frac{p^{\prime}}{p_{\text {ref }}}\right)^{n_{e}}
$$

$K_{r e f}$ and $G_{r e f}$ are the bulk and shear moduli measured at the mean reference pressure $\left(p_{\text {ref }}\right)$.

Adopting the soil mechanics sign convention (compression positive), the deviatoric primary yield surface of the $k$ plane is given by:

$$
f_{k}\left(\underline{\underline{\sigma}}^{\prime}, \varepsilon_{v}^{p}, r_{k}\right)=q_{k}-\sin \phi_{p p}^{\prime} \cdot p_{k}^{\prime} \cdot F_{k} \cdot r_{k}
$$

with:

$$
\begin{gathered}
F_{k}=1-b \ln \left(\frac{p_{k}^{\prime}}{p_{c}}\right) \\
p_{c}=p_{c o} \exp \left(\beta \varepsilon_{v}^{p}\right)
\end{gathered}
$$

where, $\underline{\underline{\sigma}}^{\prime}$ is the effective stress tensor and $\phi_{p p}^{\prime}$ is the friction angle at the critical state. The parameter $b$ controls the form of the yield surface in the $\left(p^{\prime}, q\right)$ plane and varies from $b=0$ to 1 passing from a Coulomb type surface to a Cam-Clay type one [9] (figure 4). $\beta$ is the plasticity compression modulus and $p_{c o}$ represents the critical state stress corresponding to the initial voids ratio. 


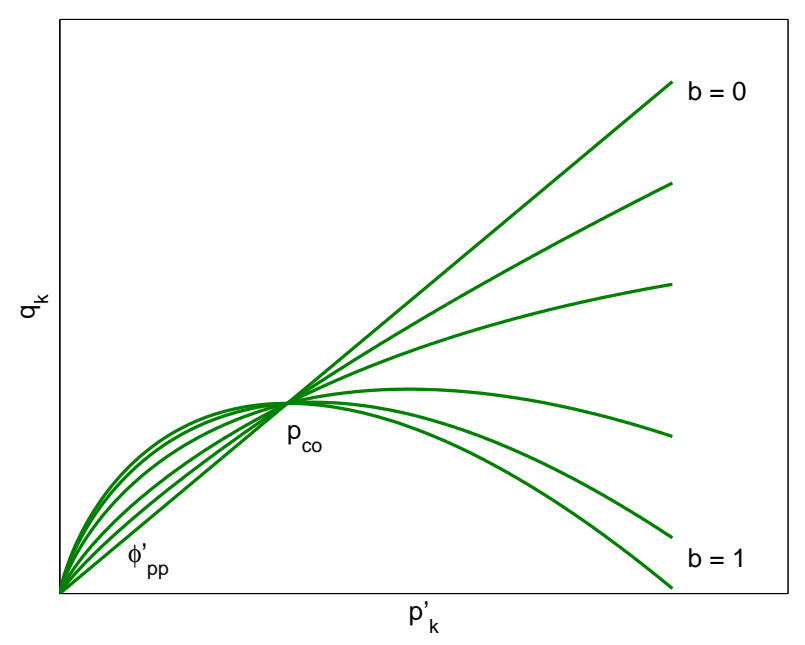

Fig. 4. Influence of parameter $b$ on the yield surface shape.

The internal variable $r_{k}$, called degree of mobilized friction, is associated with the plastic deviatoric strain. This variable introduces the effect of shear hardening of the soil and permits the decomposition of the behaviour domain into pseudo-elastic, hysteretic and mobilized domains. It is given by:

$$
r_{k}=r_{k}^{e l}+\frac{\left|\bar{\varepsilon}^{p}-\bar{\varepsilon}_{o}^{p}\right|}{a+\left|\bar{\varepsilon}^{p}-\bar{\varepsilon}_{o}^{p}\right|}
$$

$\bar{\varepsilon}^{p}$ is the plastic shear strain accumulated during the shearing $\left(\bar{\varepsilon}^{p}=\int_{t o}^{t} \dot{\bar{\varepsilon}}^{p} d t\right) ; \bar{\varepsilon}_{o}^{p}$ is the plastic shear strain accumulated from the very beginning of the loading until the last unloading $\left(\bar{\varepsilon}_{o}^{p}=\int_{0}^{t o} \dot{\bar{\varepsilon}}^{p} d t\right)$. Parameter $a$ is defined as :

$$
a=a_{1}+\left(a_{2}-a_{1}\right) \alpha_{k}\left(r_{k}\right)
$$

where :

$$
\begin{array}{ll}
\alpha_{k}=0 & \text { if } r_{k}^{\text {elas }}<r_{k}<r_{k}^{\text {hys }} \\
\alpha_{k}=\left(\frac{r_{k}-r_{k}^{\text {hys }}}{r_{k}^{\text {mob }}-r_{k}^{\text {hys }}}\right)^{m} & \text { if } r_{k}^{\text {hys }}<r<r_{k}^{\text {mob }} \\
\alpha_{k}=1 & \text { if } r_{k}^{\text {mob }}<r_{k}<1
\end{array}
$$

$a_{1}, a_{2}$ and $m$ are model parameters and $r^{h y s}$ and $r^{m o b}$ designate the extend of the domain where hysteresis degradation occurs. When the plastic strains grow dramatically in the soil, the function $r_{k}$ reaches its maximal value asymptotically:

$$
\lim _{\bar{\varepsilon}^{p \rightarrow+\infty}} r_{k}=1 \text { or } \lim _{\bar{\varepsilon}^{p \rightarrow+\infty}} q_{k}=\sin \phi_{p p}^{\prime} \cdot p_{k}^{\prime} \cdot F_{k}
$$


The isotropic yield surface is assumed to be :

$$
f_{\text {iso }}=\left|p^{\prime}\right|-d p_{c} r_{\text {iso }}
$$

with :

$$
r_{i s o}=r_{i s o}^{e l a}+\frac{\int_{0}^{t}\left|\left(\dot{\varepsilon}_{v}^{p}\right)_{i s o}\right| d t}{c \frac{p_{c}}{p_{\text {ref }}}+\int_{0}^{t}\left|\left(\dot{\varepsilon}_{v}^{p}\right)_{i s o}\right| d t}
$$

where $d$ is a model parameter representing the distance between the isotropic consolidation line and the critical state line in the $\left(\varepsilon_{v}-\ln p^{\prime}\right)$ plane (i.e. $d=$ $\left.\left|p_{i s o}^{\prime}\right| / p_{c}\right)$ and $c$ controls the volumetric hardening.

In the model, an associated flow rule in the deviatoric plane $(k)$ is assumed, and the Roscoe's dilatancy law [10] is used to obtain the increment of the volumetric plastic strain of each deviatoric mechanism so that :

$$
\dot{\varepsilon}_{v k}^{p}=\dot{\lambda}_{k}^{p} \cdot \alpha_{\psi} \cdot \alpha_{k}\left(r_{k}\right)\left(\sin \psi-\frac{q_{k}}{p_{k}^{\prime}}\right)
$$

where $\psi$ is the characteristic angle [11] defining the limit between dilatancy and contractance of the material (figure 5) and $\alpha_{\psi}$ a constant parameter.

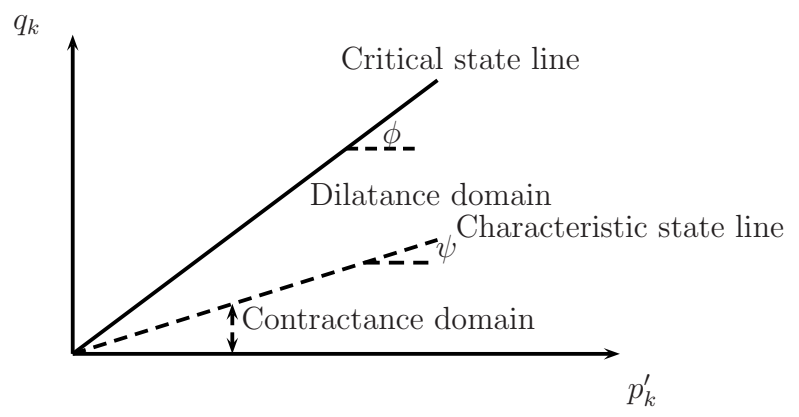

Fig. 5. Critical State and Chacteristic State Lines.

The parameters of the elastoplastic model concern both the elastic and plastic behaviour of the soil and they are separated into two categories: those that can be directly measured from either in-situ or laboratory test results and those which, cannot be directly measured (Table 2). 
Table 2

Classification of the Elastoplastic model parameters

\begin{tabular}{l|cc} 
& Directly measured & Not-Directly measured \\
\hline Elastic & $K_{r e f}, G_{r e f}, n_{e}, p_{r e f}$ & \\
Critical State and Plasticity & $\phi_{p p}^{\prime}, \beta, p_{c o}, d$ & $b$ \\
Flow Rule and Isotropic hard. & $\psi$ & $a_{1}, a_{2}, \alpha_{\psi}, m, c$ \\
Threshold domains & & $r^{e l a}, r^{\text {hys }}, r^{m o b}, r_{i s o}^{e l a}$
\end{tabular}

\section{Coupled dynamic approach}

A coupled dynamic approach derived from the $\underline{u}-p_{w}$ version of the Biot's generalized consolidation theory $[12,13]$ was adopted for the soil. Field equations consist of overall dynamic equilibrium, water equilibrium, water continuity, compatibility, constitutive law and generalized Darcy's law.

The so-called $\underline{u}-p_{w}$ formulation, which consists of neglecting fluid acceleration terms and convective terms of this acceleration so that the unknown variables remain the displacement of the solid $\underline{u}$ and the pressure of the water $p_{w}$. As further simplifications, soil grain compressibility is assumed to be null and thermal effects are neglected. The behaviour of the solid skeleton is derived assuming the principle of effective stress as proposed by Terzaghi, where the total stress tensor $(\underline{\underline{\sigma}})$ is split into two components: the effective stress tensor $\left(\underline{\underline{\sigma^{\prime}}}\right)$ and the pore pressure $\left(p_{w}\right)$. Where $\underline{\underline{\sigma}}=\underline{\underline{\sigma^{\prime}}}-p_{w} \cdot \underline{\underline{I}}$ with $\underline{\underline{I}}$ the identity second order tensor. Under such hypotheses the set of governing equations is:

- Overall equilibrium for the soil-fluid mixture

$$
\underline{\operatorname{div}} \underline{\underline{\underline{\sigma}}}^{\prime}-\underline{\nabla} p_{w}+\rho \underline{\mathrm{g}}=\rho \underline{\ddot{u}}
$$

where $\rho$ is the total average unit mass $\left(\rho=n \rho_{w}+(1-n) \rho_{s}\right) ; n$ is the soil porosity; $\rho_{w}$, the fluid mass; $\rho_{s}$, the soil particle mass; $\underline{g}$, the gravity acceleration vector and $\underline{u}$ is the solid skeleton displacement.

- Equilibrium of the water and flow conservation equation using generalized Darcy's law. Assuming each phase as homogeneous:

$$
\begin{aligned}
& \underline{v}_{r w}=\underline{\underline{k}}\left[-\underline{\nabla} p_{w}+\rho_{w}\left(\underline{\mathrm{g}}-\partial_{t} \underline{v}_{w}\right)\right] \\
& \underline{\operatorname{div} \underline{v}_{r w}}+\underline{\operatorname{div} \dot{u}}+\frac{n}{K_{w}} \underline{\dot{p}}_{w}=0
\end{aligned}
$$

where $\underline{v}_{r w}$ is the mean fluid velocity relative to the solid phase; $\underline{\underline{k}}$ is the permeability tensor; $K_{w}$ is the fluid compressibility; $\partial_{t}$, the partial derivative with respect to time and $\underline{v}_{w}$ is the fluid absolute velocity. 


\section{$5 \quad$ Used soil material}

The model parameters of each layer were determined with the methodology explained in [14-16]. They are summarized in the table 3.

Table 3

ECP model's parameters for all soil profile layers.

\begin{tabular}{lccccc} 
& $0-2 m$ & $2-9 m$ & $9-16 m$ & $16-22 m$ & $22-29 m$ \\
\hline$k_{s}(m / s)$ & $1 \cdot 10^{-2}$ & $1 \cdot 10^{-5}$ & $1 \cdot 10^{-5}$ & $1 \cdot 10^{-4}$ & $1 \cdot 10^{-4}$ \\
Elasticity & & & & & \\
$K_{\text {ref }}(M P a)$ & 90.0 & 628.0 & 628.0 & 628.0 & 444.0 \\
$G_{r e f}(M P a)$ & 45.0 & 290.0 & 290.0 & 290.0 & 222.4 \\
$n_{e}$ & 0.00 & 0.50 & 0.50 & 0.50 & 0.40
\end{tabular}

Critical State and Plasticity

$\begin{array}{lccccc}\phi_{p p}^{\prime}\left({ }^{\circ}\right) & 31 & 30 & 30 & 30 & 31 \\ \beta & 20 & 33 & 33 & 33 & 43 \\ d & 2.00 & 2.00 & 2.00 & 2.00 & 3.50 \\ b & 0.20 & 0.20 & 0.20 & 0.20 & 0.20 \\ p_{c o}^{\prime}(M P a) & 1.86 & 0.04 & 0.05 & 0.08 & 1.80\end{array}$

Flow Rule and Isotropic Hardening

$\begin{array}{lccccc}\psi\left({ }^{\circ}\right) & 31 & 30 & 30 & 30 & 31 \\ a_{1} & 0.0001 & 0.0001 & 0.0001 & 0.0001 & 0.0001 \\ a_{2} & 0.0002 & 0.0050 & 0.0050 & 0.0050 & 0.0040 \\ c_{1} & 0.0010 & 0.0040 & 0.0040 & 0.0040 & 0.0600 \\ c_{2} & 0.0005 & 0.0020 & 0.0020 & 0.0020 & 0.0300 \\ m & 1.00 & 1.50 & 1.50 & 1.50 & 1.00\end{array}$

Threshold Domains

\begin{tabular}{lccccc}
$r^{\text {ela }}$ & 0.013 & 0.030 & 0.030 & 0.030 & 0.005 \\
$r^{\text {hys }}$ & 0.220 & 0.040 & 0.040 & 0.040 & 0.030 \\
$r^{m o b}$ & 0.800 & 0.800 & 0.800 & 0.800 & 0.800 \\
$r_{\text {iso }}^{\text {ela }}$ & 0.0040 & 0.0200 & 0.0200 & 0.0200 & 0.0010 \\
\hline
\end{tabular}

For all cases $p_{r e f}=1.0 M P a$ and $\alpha_{\psi}=1$.

In order to verify the model's parameters and to characterize the liquefaction resistance of sand placed between 3.5 and $9 \mathrm{~m}$ depth, the behaviour of the sand must be studied by simulating drained cyclic shear tests $(D C S)$ and undrained stress controlled cyclic shear tests.

Figure 6 shows the responses of these $D C S$ tests obtained by the model of the loose sand at $\sigma_{m o}^{\prime}=40$ and $80 \mathrm{kPa}$. The tests results are compared with the reference curves given by Seed et al. [17]. We can notice that the obtained 
$G / G_{\max }-\gamma$ curves match relatively good though for strains less than $0.01 \%$ the damping $D$ is underestimated while for large strains it is overestimated.
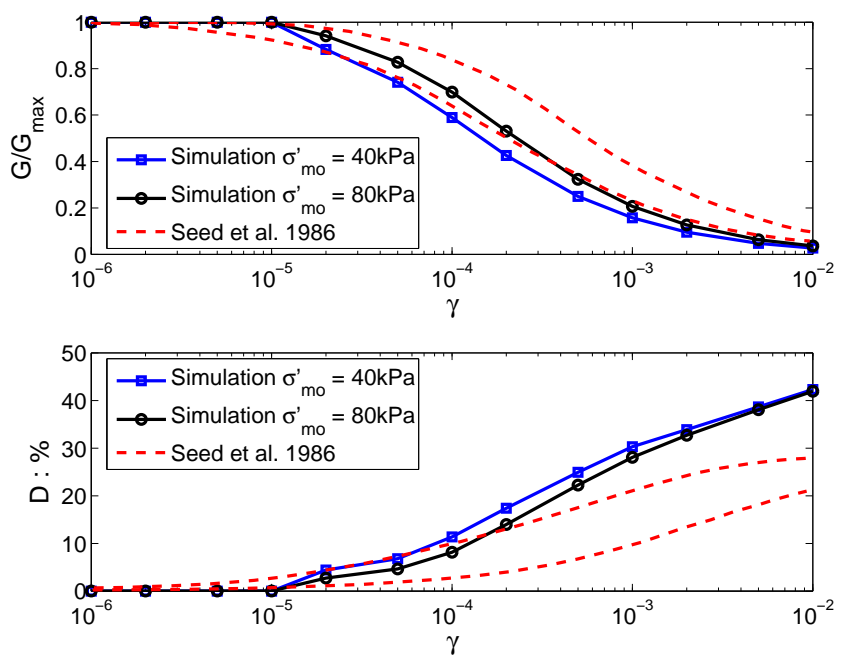

Fig. 6. Comparison between simulated and reference curves obtained by Seed et al. $[17]$

The obtained curve of cyclic stress ratio $\left(\tau / \sigma_{m}^{\prime}\right)$ as a function of the number of loading cycles to produce liquefaction $(N)$ at $\sigma_{m}^{\prime}=40 \mathrm{kPa}$ is given in figure 7 . The modelled test result is compared with the reference curves given by Seed and Idriss [18] for sands at different densities (i.e. SPT values). We can notice that the obtained curve matches relatively good with the one corresponding to $S P T-N_{60}=5$.

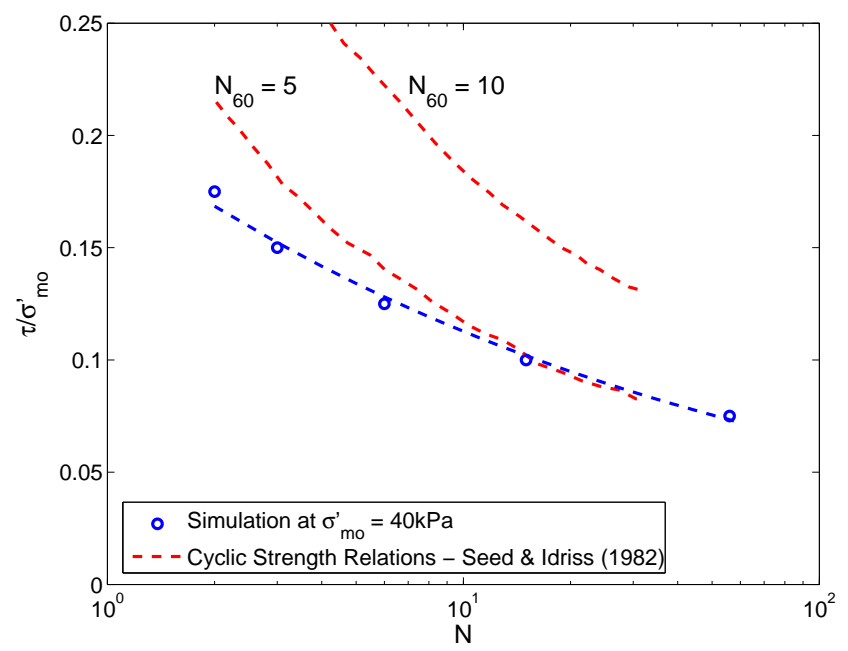

Fig. 7. Comparison of simulated sand model liquefaction curves with cyclic strength relations. 


\section{$6 \quad$ Non-linear elastoplastic model analysis}

\subsection{Free field response}

In order to define both the depths where, and the acceleration level at which the liquefaction takes place, the response of the site profile is computed using the horizontal component of the input records. The maximum acceleration at the outcropping bedrock $\left(P G A_{\text {outc }}\right)$ is scaled to different values (i.e. from 0.15 to $0.4 \mathrm{~g})$ corresponding to different levels of Arias intensities $\left(I_{\text {Arias }}\right)[3]$.

\subsubsection{Liquefaction analyses}

In order to define the depth and thickness of the zones where liquefaction takes place, it is interesting to compare the induced pore pressure excess $\left(\Delta p_{w}\right)$ distribution with depth at the end of the signal (i.e. coseismic analyses) for different input acceleration levels (i.e. $a_{\max \text { bed }}$ ) (Figure 8).

Let $T_{\text {soil }}$ be the first elastic period of the soil deposit, obtained from the transfer function at free field (i.e. ratio of the frequency response at the soil surface over the bedrock frequency response). According to figure $8 \mathrm{a}$ and $\mathrm{b}$, in the case of earthquakes with mean periods $\left(T_{m}\right)$ much lower than $T_{\text {soil }}$ (i.e. $0.57 \mathrm{~s}$ ), the liquefaction phenomena occurs principally at layers between 3 and $6 \mathrm{~m}$ depth and for bedrock acceleration levels $\left(a_{\text {max bed }}\right)$ bigger than $0.1 \mathrm{~g}$. When the $T_{m}$ value of the earthquake is near to $T_{\text {soil }}$, the liquefaction zone is placed between 4 and $8 \mathrm{~m}$ depth when $a_{\text {max bed }}$ is greater than $0.13 \mathrm{~g}$ (Figure $8 \mathrm{c}$ ). On the other hand, we can note that for larger $T_{m}$ values the liquefaction is concentrated principally in a deeper zone (i.e. 8 to $10 \mathrm{~m}$ ) with $a_{\text {max bed }}$ greater than $0.12 \mathrm{~g}$ (Figure $8 \mathrm{~d}$ ). These conclusions agree with those found by Koutsourelakis et al. [19] and Popescu [20].

As far as it concerns the induced shear strains $\left(\gamma_{\text {ind }}=0.65 \cdot \gamma_{\max }\right)$ in the soil profile (Figure 9), it is noted that the onset of liquefaction coincides with the apparition of large shear strain (i.e. $\gamma_{\text {ind }} \geq 2 \%$ ). These shear strain levels correspond to bigger levels of soil stiffness degradation, (i.e. $G / G_{\max } \approx 0$; figure 6).

\subsubsection{Ground response analysis}

In the practice the most common approach for evaluating the liquefaction resistance of soil profiles is the "simplified procedure" proposed by Seed and Idriss [21]. In this methodology, two variables are required to evaluate the liquefaction resistance of soils: the seismic demand on a soil layer $(C S R)$ and 


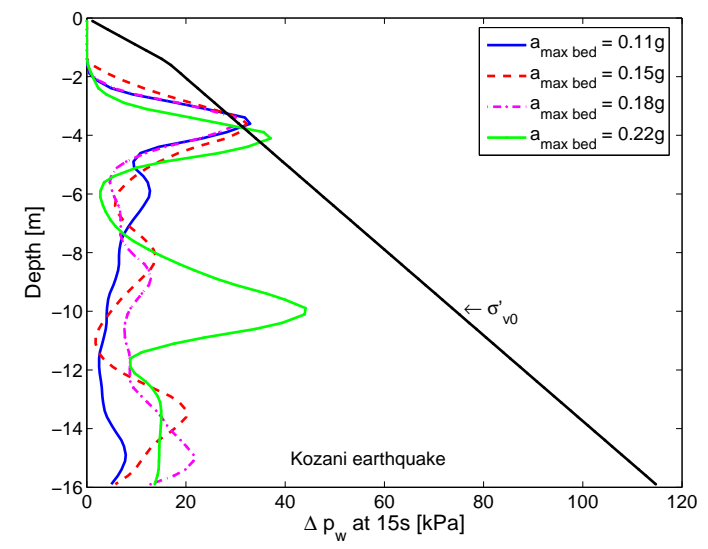

a.

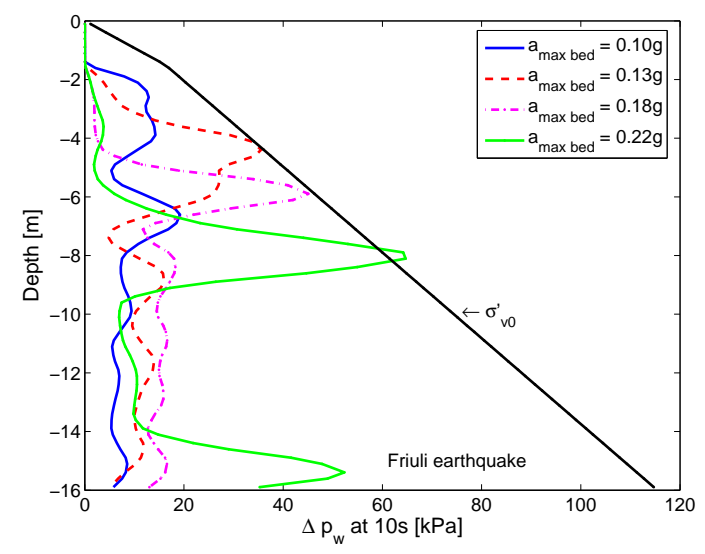

c.

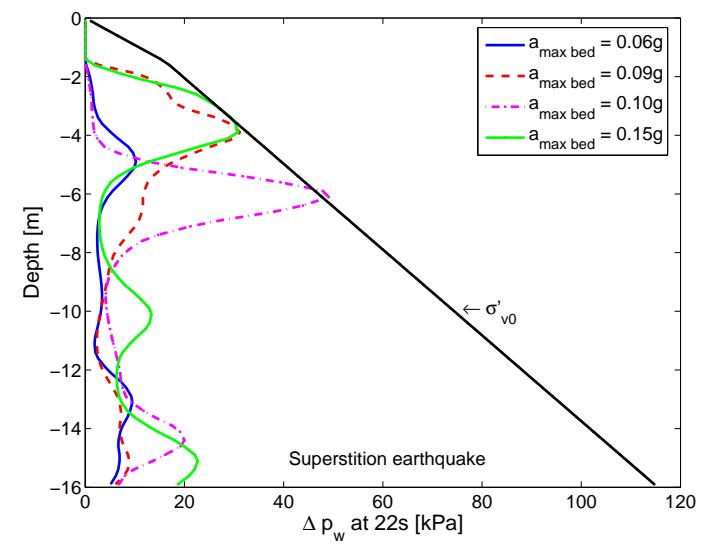

b.

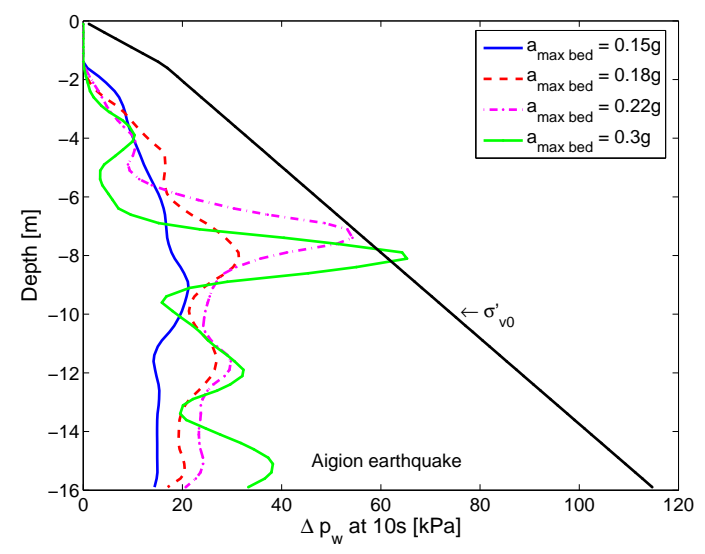

d.

Fig. 8. Obtained pore pressure excess in the soil profile for different $a_{\max }$ values; evolution of maximum value with depth : a) for Kozani earthquake, b) for Superstition earthquake, c) for Friuli earthquake and d) for Aigion earthquake.

the capacity of the soil to resist to liquefaction $(C R R)[21,22]$. In order to evaluate the value of $C S R$, Seed and Idriss [21] propose an equation where the peak horizontal acceleration at the ground surface $\left(P G A_{\text {surf }}\right)$ is the most important variable.

To estimate the $P G A_{\text {surf }}$ value, Youd et al. [22] recommend to use attenuation relationships such as those given by Idriss [23] or Dickenson and Seed [24], but even if this kind of relations take into account the influence of non linearity of soil behaviour in the site amplification, they neglect the influence of excess pore-water pressure in the $P G A_{\text {surf }}$ value.

As far as it concerns the acceleration history obtained at the surface in our analyses, two aspects are interesting to study : the effect of the soil behaviour on the obtained acceleration at the surface level $\left(P G A_{\text {surf }}\right)$ and the variation of the frequency content of the output signal. 


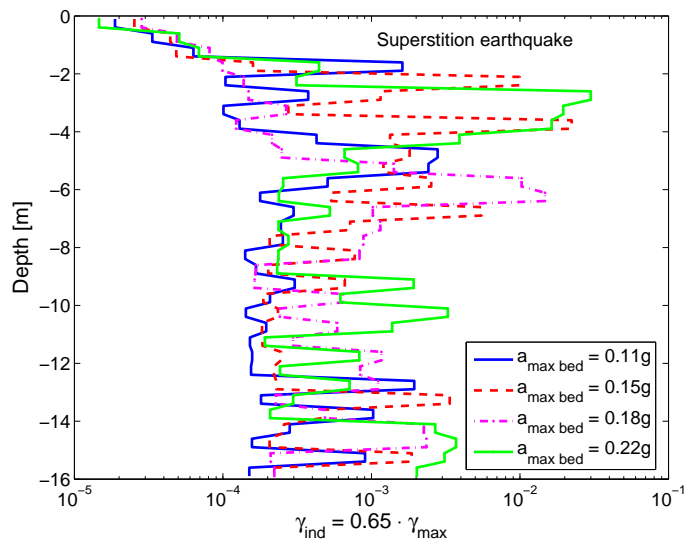

a.

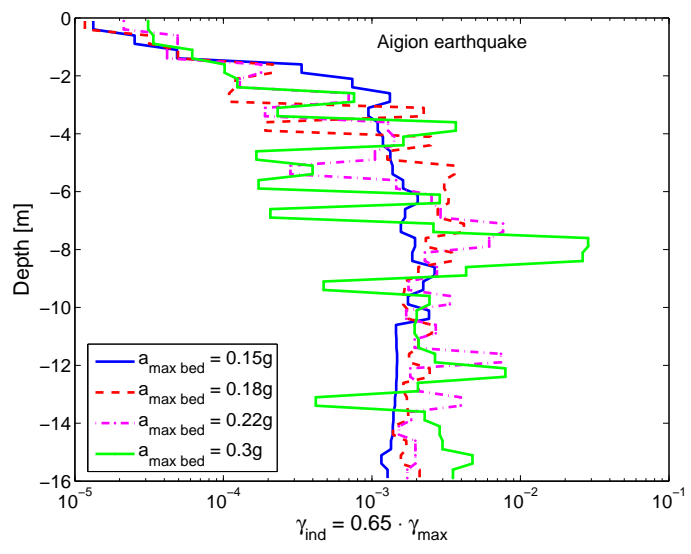

b.

Fig. 9. Evolution of induced cyclic shear strain $\gamma_{\text {ind }}$ with depth obtained for : a) Superstition earthquake and b) Aigion earthquake, scaled to different amplitudes.

Figure 10 shows the variation of peak ground acceleration at the surface $\left(P G A_{\text {surf }}\right)$ as a function of the maximum acceleration at the more rigid layer situated at $29 \mathrm{~m}$ depth which can be considered as the bedrock $a_{\max }$ bed. According to this figure, the amplification of peak ground acceleration on the ground surface relative to bedrock appears before $a_{\text {max }}$ bed value equal to $0.12 \mathrm{~g}$. After this value, the non linear behaviour of soil profile, due principally to the apparition of liquefaction phenomenon, produces an attenuation of the seismic motion observed at the ground surface. It can also be seen that the amplification of acceleration at the surface is much smaller than those proposed by Idriss [25] and Dickenson and Seed [24].

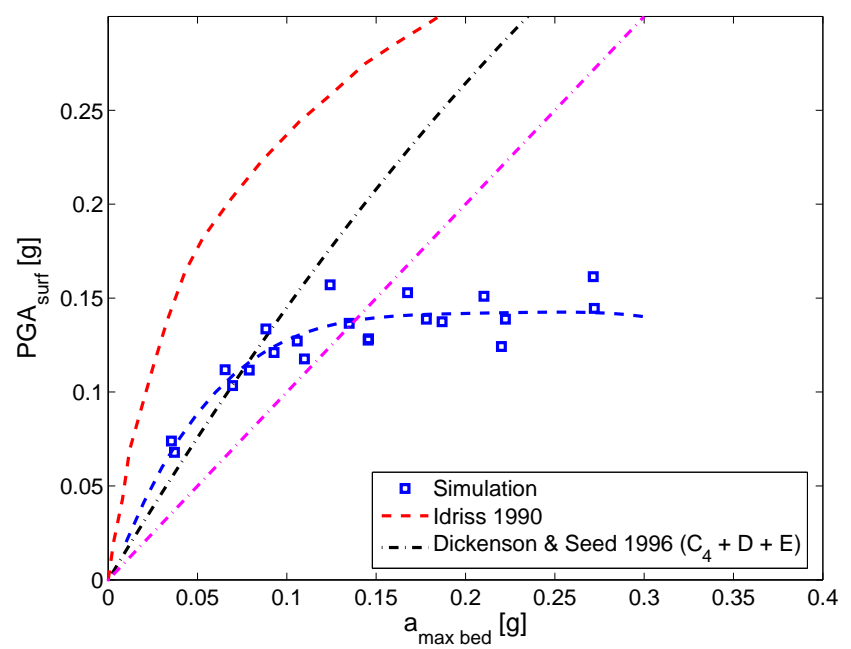

Fig. 10. Relationships between maximum accelerations on bedrock and surface obtained in the soil profile for different earthquakes.

Furthermore, a modification of the frequency content in the surface ground motion due to liquefaction apparition is also observed (Figure 11). According 
to this figure, the apparition of motion with longer period at the ground surface is correlated with the increase of pore water pressure and the presence of liquefaction (i.e. pore pressure ratio $R_{u} \approx 1 ; R_{u}=\Delta p_{w} / \sigma_{v o}^{\prime}$ ). According to Ghosh and Madabhushi [26], the liquefaction zone is associated with lower shear wave velocity and thus the generation of excess pore water pressure in this region will drop the natural frequency of the soil profile.
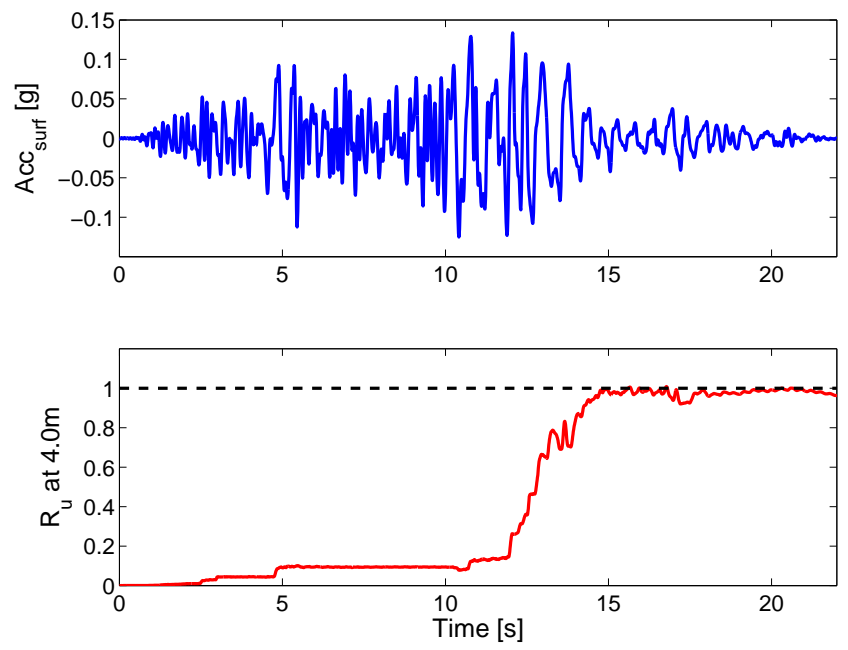

Fig. 11. Obtained ground surface acceleration and pore pressure ratio $R_{u}$ at $4.0 \mathrm{~m}$ depth for Superstition earthquake input motion.

This phenomena have been also observed in the field and reported by several authors [27-30].

The comparison between the bedrock response spectra and the one obtained at the surface for different acceleration levels (Figure 12), indicates that the increase of pore pressure induces a reduction of short period (i.e. periods less than about $0.5 \mathrm{~s}$; figure $12 \mathrm{~b}$ ) spectral accelerations. However, for periods larger than about $0.5 \mathrm{~s}$, surface spectral accelerations are greater than the bedrock accelerations. This difference is more important when the bedrock acceleration increases and the apparition of liquefaction takes place, as the soil softening is greater.

\subsection{SSI analyses}

\subsubsection{Effects of structure in the liquefaction response at Free Field}

In the current practice, in order to quantify the structural damage induced by liquefaction, several methodologies are proposed. In these methodologies the assessment of liquefaction potential is performed using published relationships between the in situ soil properties and the cyclic shear stress induced by ground shaking e.g. Seed and Idriss [21] among others [31,32]. It is well 


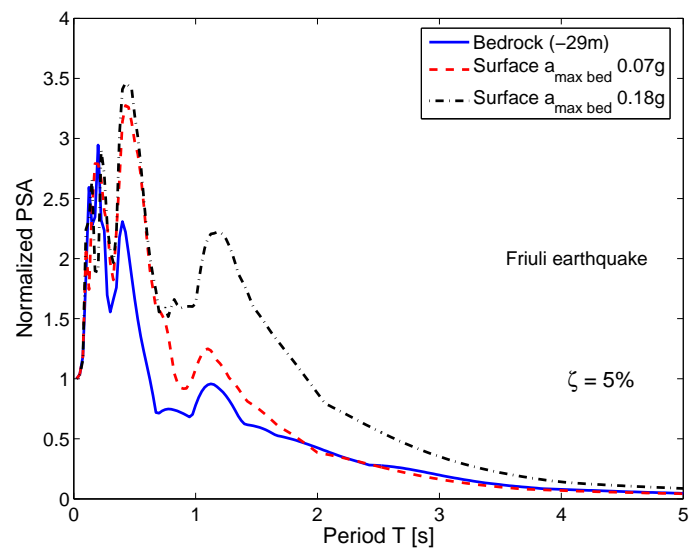

a.

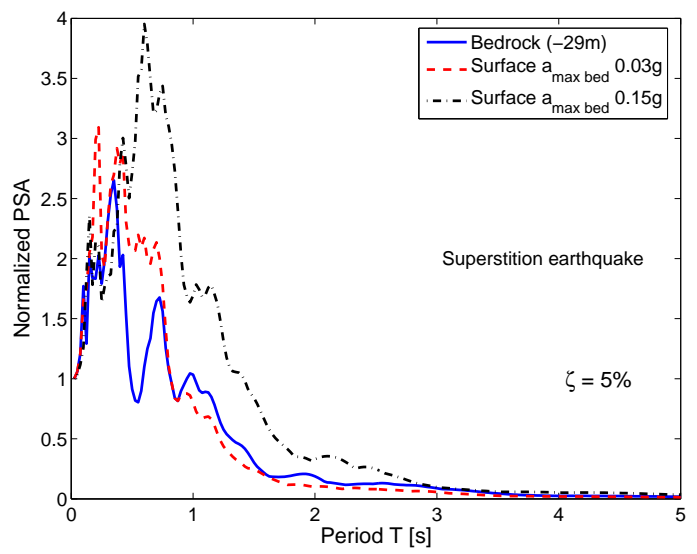

b.

Fig. 12. Comparisons between bedrock and surface response spectra for different acceleration levels for : a) Friuli earthquake and b) Superstition earthquake.

known that these semi-empirical procedures were developed to determine the liquefaction potential of soil profiles in free field conditions.

As far as it concerns the modification of the response of soil profile in free field condition due to the presence of the structure, the responses obtained in a soil profile $10 \mathrm{~m}$ far from the shallow foundation of the structure $\left(F F_{S D O F}\right)$ are compared with those obtained in a real free field condition $(F F)$ (section $6.1 .1)$.

According to figure 13, two observations may be noted : (i) the pore water pressure distribution at the end of the earthquake motion is modified by the presence of the structure, even if the soil profile is far from it. This difference is due principally to redistribution of pore water pressure bellow the structure and the stresses induced by the oscillation of the structure. (ii) the effect of the structure on the response of the free field is not the same and it seems that it depends on both the frequencies of the structure and the input signal.

As recalled before, regarding the ground surface motion it is necessary to compare the variations of output signal in both acceleration level and frequency content. The acceleration response spectra for the ground surface motions obtained with the Kozani earthquake with $a_{\max }$ bed $=0.15 \mathrm{~g}$ are shown in figure 14. It may be seen that the three responses are in overall similar, discrepancies occurring only in periods greater than $0.6 \mathrm{~s}$ where an amplification of spectral acceleration appears due to the presence of the structure.

Finally, it can be noticed from figure 15 that the average relationship between $P G A_{\text {surf }}$ and $a_{\text {max bed }}$ obtained in the case of free field remains valid and it is not affected by the proximity of the structure. 


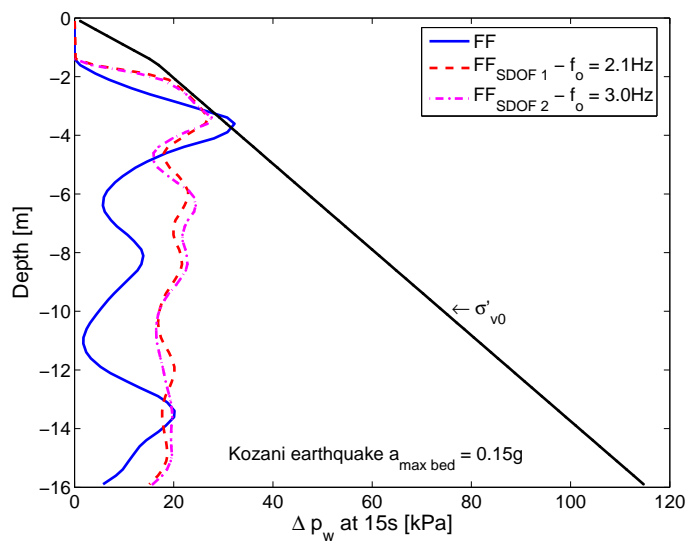

a.

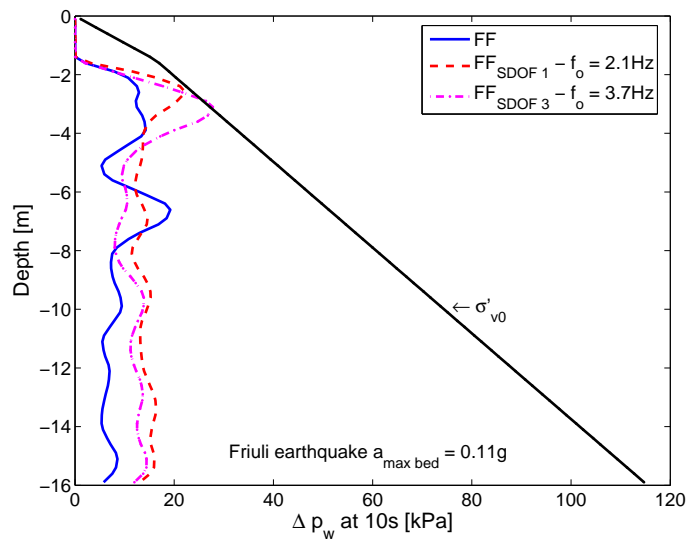

b.

Fig. 13. Effect of the presence of a structure on the obtained pore pressure excess at free field condition soil profile $(10 \mathrm{~m}$ far). Evolution of maximum value with depth : a) Kozani earthquake and b) Friuli earthquake.

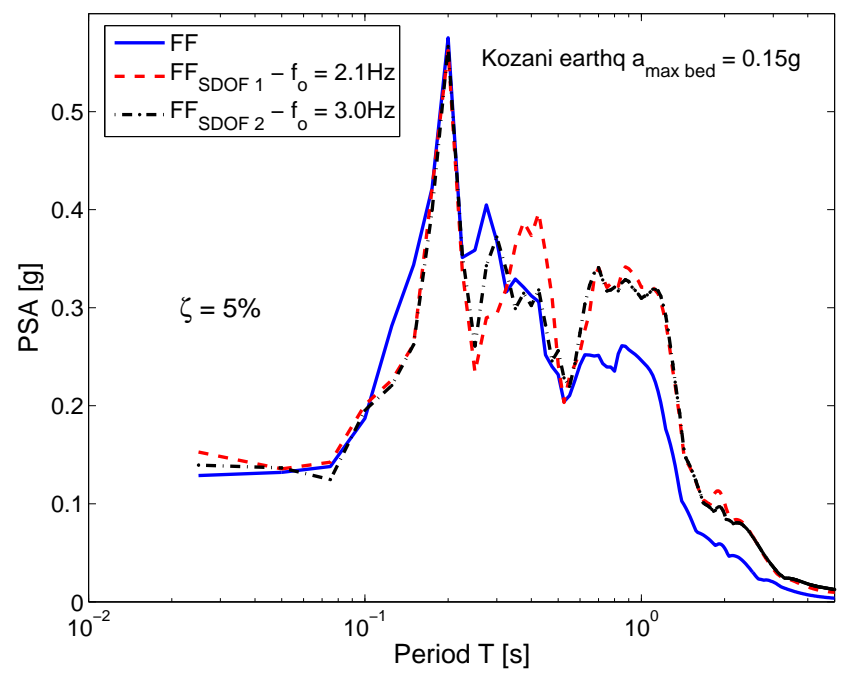

Fig. 14. Ground acceleration response spectra at free field surface.

\subsubsection{Liquefaction bellow the shallow foundation}

The presence of the structure creates an increment in the overburden pressure in the soil bellow the foundation and thus has a significant effect on the pore pressure build up. In this condition a modification of both the depth and the acceleration level at which the liquefaction takes place is expected with respect to the free field case.

It can be noted from the obtained pore pressure excess in the soil profile bellow the foundation of SDOF 1 (Figure 16 a), that the liquefaction zone during the Friuli earthquake is placed at layers between 2 and $4 \mathrm{~m}$ depth. For the same earthquake the liquefaction zone takes place at deeper layers when the analysis is carried out without the structure (Figure $8 \mathrm{c}$ ). The comparison 


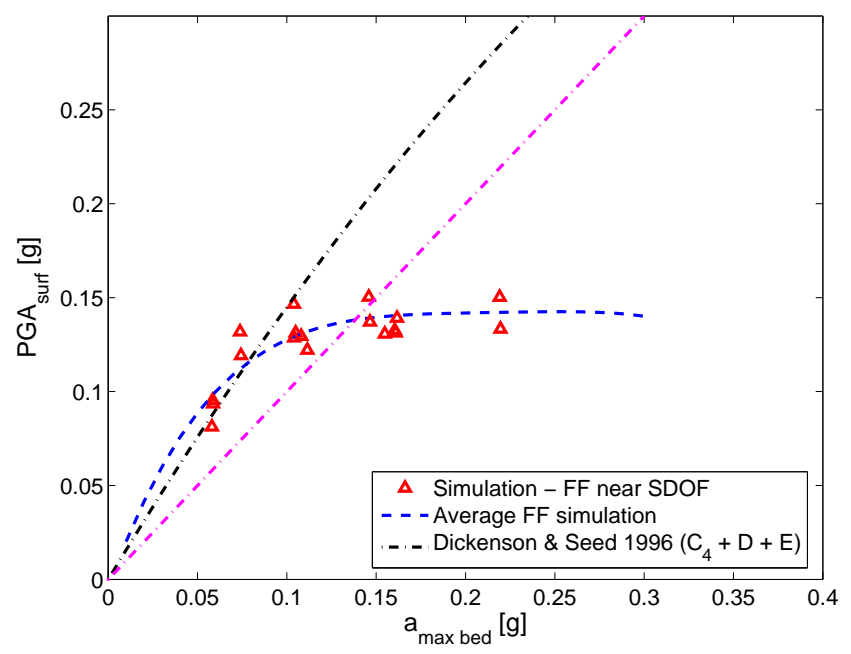

Fig. 15. Relationships between maximum acceleration on bedrock and surface obtained in the soil profile near to SDOF for different earthquakes.

made of pore pressure excess for the same earthquake with the three SDOF structures shows that the effect of structural frequency can be neglected on the pore pressure distribution (Figure $16 \mathrm{~b}$ ).

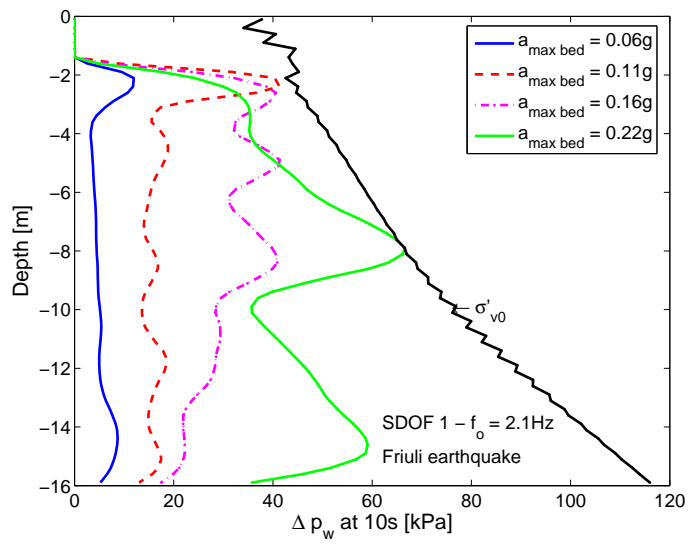

a.

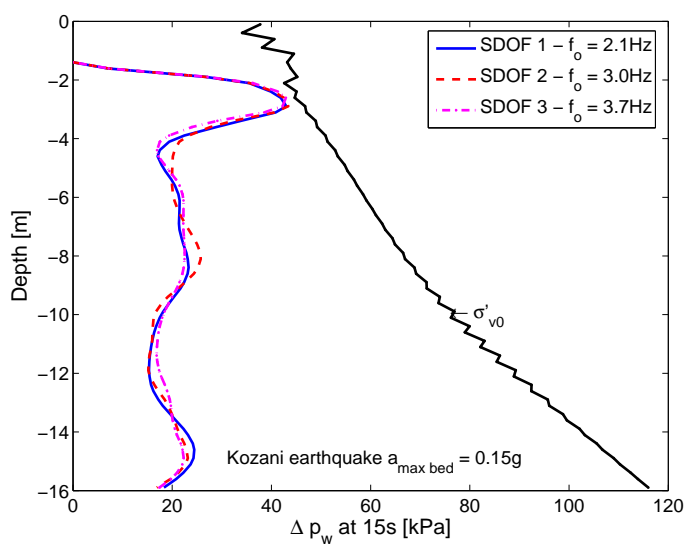

b.

Fig. 16. Obtained pore pressure excess in the soil profile bellow the foundation; evolution of maximum value with depth : a) Friuli earthquake and b) Kozani earthquake.

\subsubsection{Effects of liquefaction in modifying seismic SSI}

Traditionally, the soil-foundation-structure interaction phenomenon is studied with the assumption of the linear elastic behaviour of the soil. Several works were carried out in order to evaluate the soil non-linearity effect on the response of soil-structure system using physical or numerical simulations. These works regard principally the degradation of soil rigidity in clays [33,34]. Among numerical works studying effects of soil liquefaction on the structure response 
we can mention Koutsourelakis et al. [19], Popescu [20], Chakrabortty et al. [35] and Popescu et al. [36]. According to these works the local subsoil conditions influences the seismic response of structures changing the characteristics of the strong motion.

In this section, the influence of soil behaviour non-linearity, introduced by the liquefaction, on the soil-foundation-structure interaction is evaluated.

Before proceeding to the analysis of liquefaction effects, a computation of the soil-structure interaction phenomenon assuming linear elasticity for the soil behaviour is performed. Thus, transfer functions for the soil and the structure are computed, as well as the soil-structure interaction transfer function, given by the ratio of the frequency response on the top of the structure over the free field frequency response. Figure 17 shows the transfer function for the structures founded on fixed base as well as the one of the soil foundation at free field $(F F)$. According to the transfer function at free field, the first natural frequency of the soil profile $f_{\text {soil }}$ is found to be, for the linear elastic case, at $1.75 \mathrm{~Hz}$ (i.e. $T_{\text {soil }}=0.57 \mathrm{~s}$ ).

As expected, the $S D O F 3$, being more rigid than both the SDOF 1 and the soil (i.e. $f_{\text {soil }}<f_{\text {str } 1}<f_{\text {str } 3}$ ), presents a more important interaction with the soil foundation (Figure 18 and Table 4).

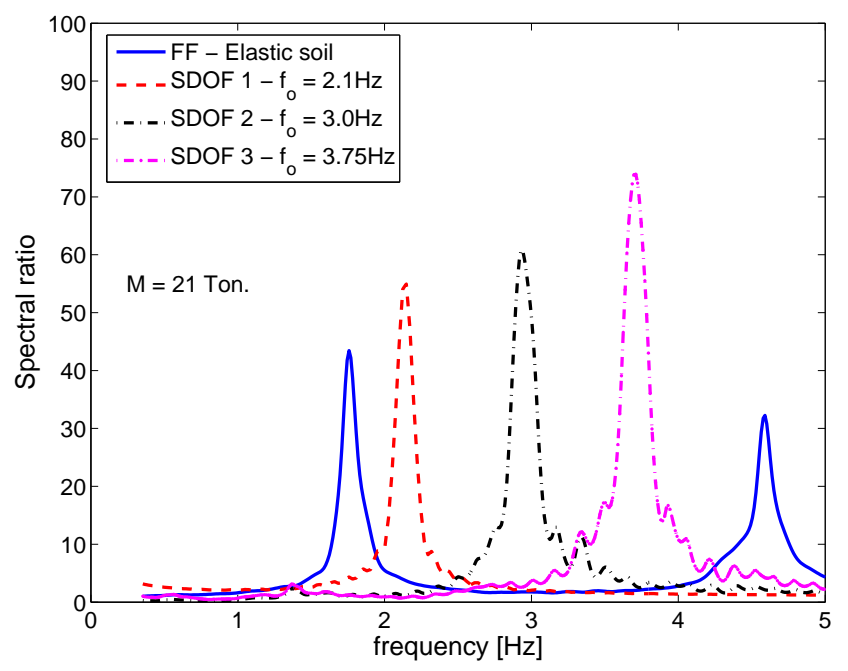

Fig. 17. Transfer functions for the used soil and structure in the elastic analyses.

Table 4

Variation of SDOF frequencies in elastic computation

\begin{tabular}{c|ccc} 
& $f_{\text {str }}(H z)$ & $f_{\text {str }} \cdot T_{\text {soil }}$ & $f_{\text {ssi }}(H z)$ \\
\hline SDOF 1 & 2.16 & 1.20 & 2.09 \\
SDOF 2 & 2.93 & 1.70 & 2.82 \\
SDOF 3 & 3.71 & 2.15 & 3.42
\end{tabular}




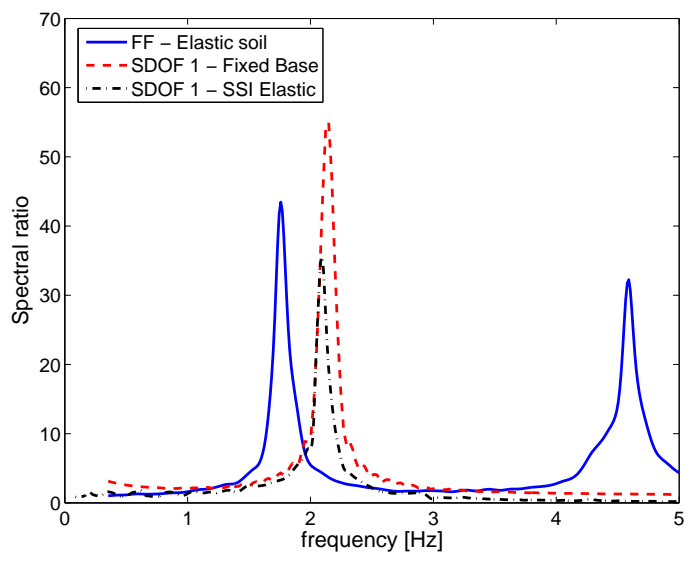

a.

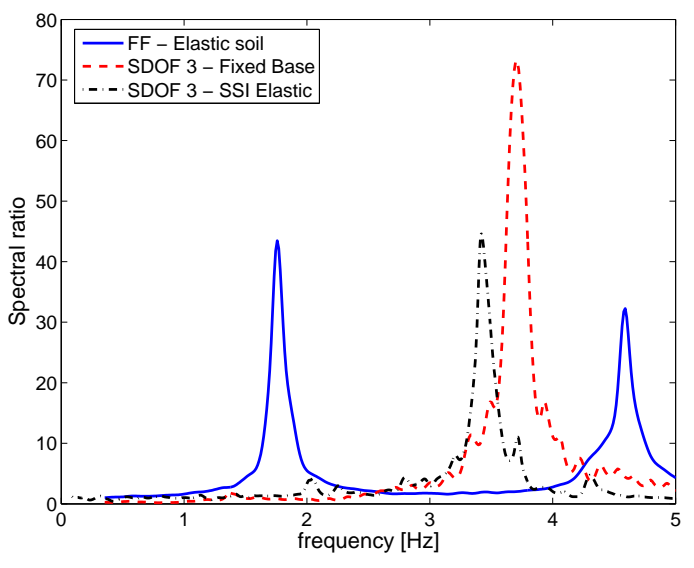

b.

Fig. 18. Obtained soil-structure interaction transfer functions in the elastic analyses : a) $S D O F 1$ and b) $S D O F 3$.

It is noted that there is a shifting in the fundamental frequency of the SDOF 3 to lower values, decaying from $3.75 \mathrm{~Hz}$ at fixed base conditions $\left(f_{\text {str } 3}\right)$ to $3.42 \mathrm{~Hz}\left(f_{s s i} 3\right)$, when the foundation is free to follow the ground movement, as well as to rotate. Furthermore, at the resonance frequency of soil-structure interaction (i.e. $f_{\text {ssi } 3}=3.42 \mathrm{~Hz}$ ), the amplitude of the response of the structure is lower than the one at fixed base. In the case of SDOF 1 (Figure $18 \mathrm{a}$ ), no significant soil-structure interaction effects take place (i.e. $f_{\text {ssi } 1}=2.09 \mathrm{~Hz}$ and $\left.f_{\text {str } 1}=2.16 \mathrm{~Hz}\right)$.

Now, if the effect of the non linear soil behaviour and the pore pressure build up are taken into account, it is interesting to note that for $S D O F 1$, the frequency of non linear soil-structure interaction $f_{s s i N L} 1$ is more and less the same as the one in elastic analysis (i.e. $f_{\text {ssiNL } 1}=2.03 \mathrm{~Hz}$ and $f_{\text {ssi } 1}=2.09 \mathrm{~Hz}$ ) (Figure 19) even if the liquefaction appears (see figure $16 \mathrm{~b}$ ). However, the amplitude of the response decreases from the elastic condition due to the soil's stiffness degradation and higher energy dissipation. For this case, the input motion is the Kozani earthquake record with bedrock acceleration level $\left(a_{\max \text { bed }}\right)$ equal to $0.15 \mathrm{~g}$.

As far as it concerns the response of $S D O F 3$ (i.e. more soil structure interaction effect in elastic analyses), two levels of input acceleration are interesting to study: moderate and strong earthquakes (i.e. $a_{\text {max bed }}$ equals to 0.05 and 0.15 g respectively).

According to the computations (Figure 20), in the case of moderate earthquake, it can be seen that the frequency of non linear soil-structure interaction $f_{\text {ssiNL } 3}$ is similar to the one in elastic analysis and the soil non-linearity regards only the amplitude of the structure's response. Nevertheless, with the strong earthquake, the response is totally damped and the behaviour of the 


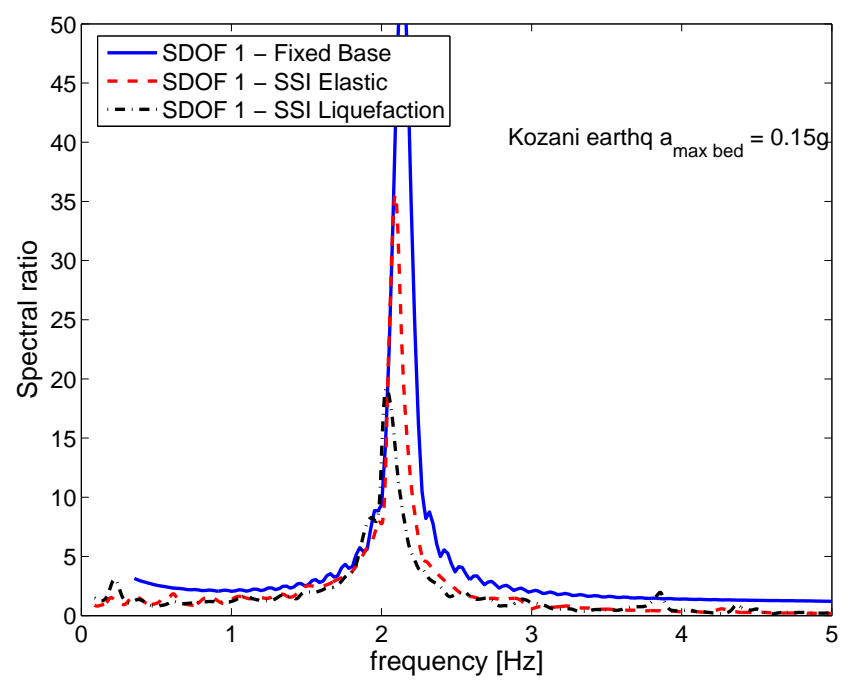

Fig. 19. Obtained soil-structure interaction transfer function in non linear analyses for $S D O F 1$ with Kozani earthquake at $a_{\max }$ bed $=0.15 \mathrm{~g}$.

structure becomes as a rigid body rather than a flexible structure. It can be explained by the modification of the frequency content of the surface ground motion due to apparition of liquefaction (Figure 12).

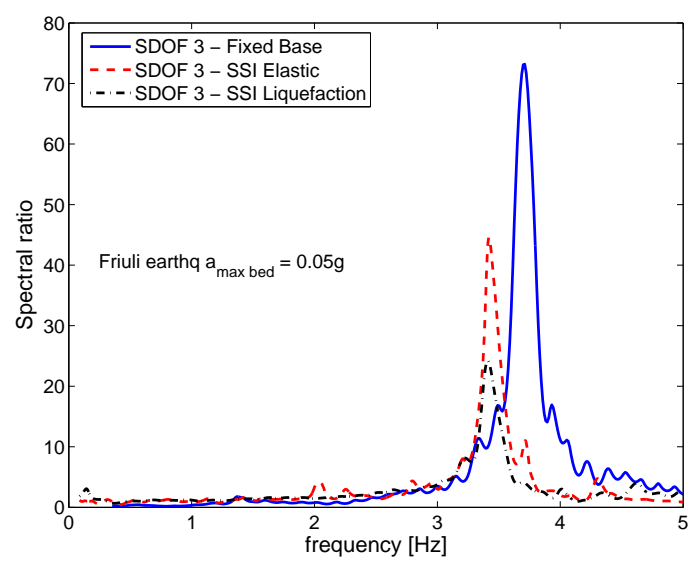

a.

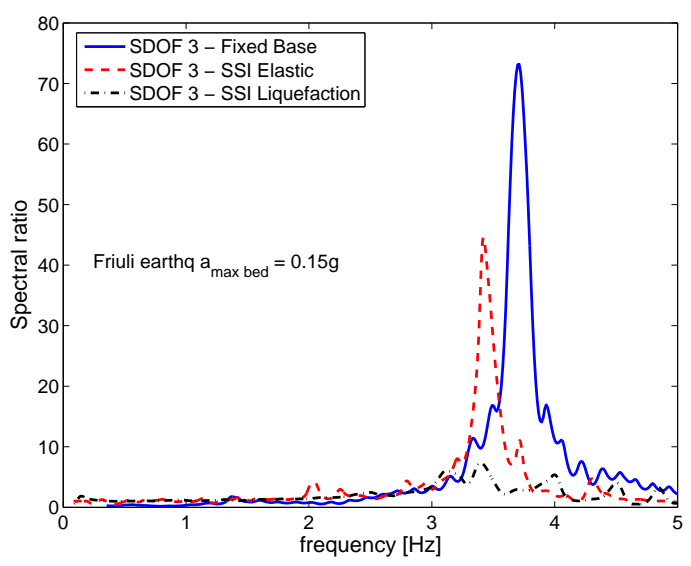

b.

Fig. 20. Obtained soil-structure interaction transfer functions in non linear analyses for $S D O F 3$ with Friuli earthquake at : a) $a_{\max \text { bed }}=0.05 \mathrm{~g}$ and b) $a_{\max }$ bed $=0.15 \mathrm{~g}$.

This damping behaviour induced by soil liquefaction is confirmed with the decrease of structural drift (i.e. relative horizontal displacement between the top and the base of structure) experienced in SDOF 3 compared to SDOF 1 for the same input acceleration level (Figure 21).

It is noted in figure 22 that the structural drift obtained for the $S D O F 1$ (i.e. $f_{\text {str }} \cdot T_{\text {soil }}=1.2$ ) is always higher than the ones obtained for SDOF 2 and $S D O F 3$. Moreover, for $S D O F 1$ in the case where the $T_{m}$ of input earthquake corresponds to the frequency of the structure, a resonant behaviour is found 


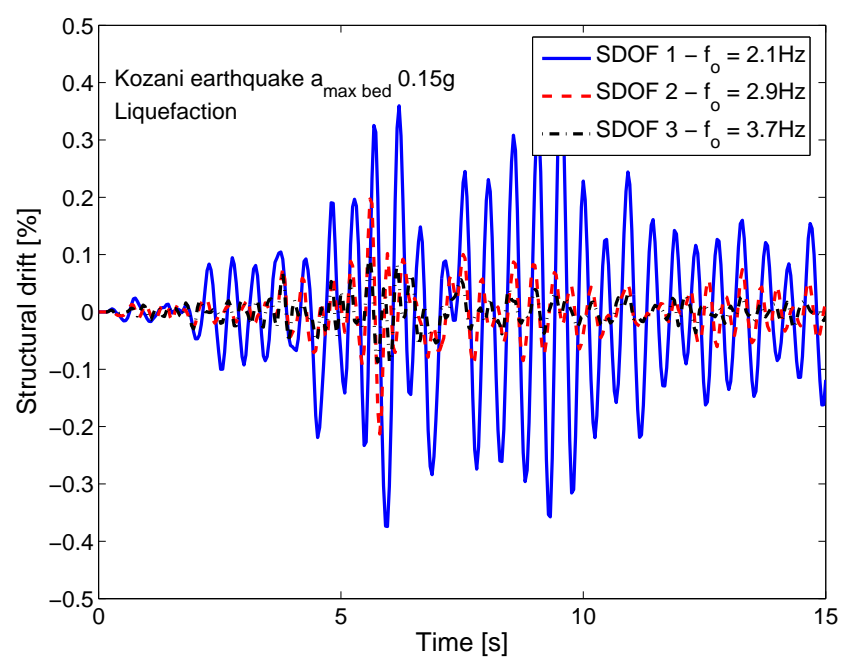

Fig. 21. Comparison of obtained structural drift in non linear analyses for $S D O F 1$, $S D O F 2$ and $S D O F 3$ with Kozani earthquake at $a_{\max }$ bed $=0.15 \mathrm{~g}$.

$\left(f_{s t r} \cdot T_{m}=1.0\right)$. It means that, in the case of large amplitude motion produced by liquefaction phenomena in the soil foundation, the structural damage in structures with significant soil-structure interaction effects may be reduced due to the local effects, so, the structure can be considered as a rigid body. Furthermore, for structures without soil-structure interaction, the response of the structure is principally in flexion mode, thus the structure can present structural damage (i.e. damage in the structural elements due to the large induced deformations) related to the liquefaction phenomena.

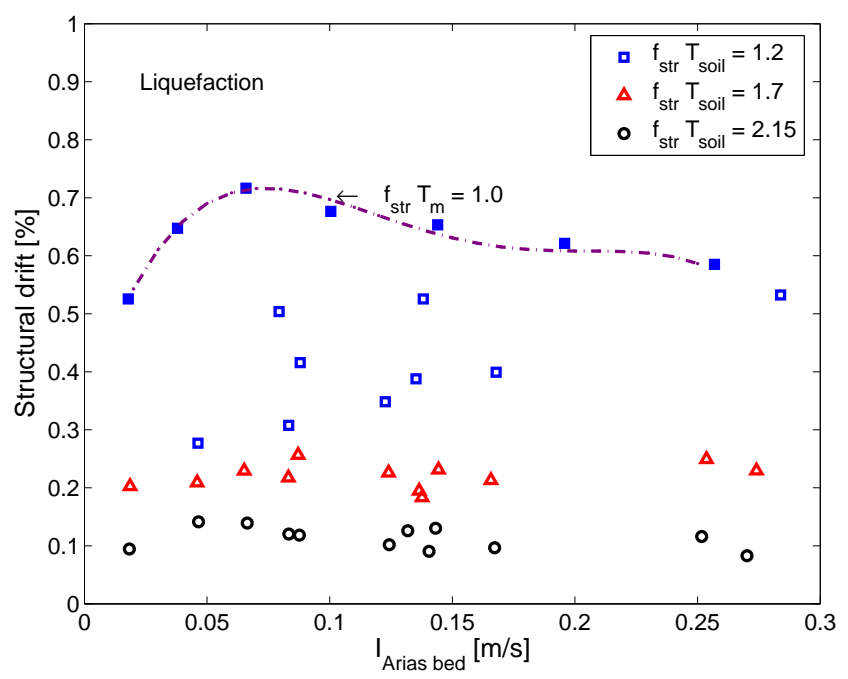

Fig. 22. Comparison of obtained structural drift as a function of $I_{\text {Arias }}$ of the signal at bedrock, in all non linear cases analysed.

This phenomenon of SSI added to the foundation type [32] can explain the response of collapsed structures observed during the recent earthquakes, as it is reported by Tokimatsu et al. [28] and Juang et al.[31] among others. A similar 
response has been reported in numerical and physical tests $[37,38,19,26,35,36]$.

Finally, as far as it concerns the coseismic settlement induced by the liquefaction and according to figure 23 two observations may be made : (i) as expected earthquakes with longer $I_{\text {Arias }}$ produce larger coseismic settlement and (ii) a higher level of settlement is found when the fundamental soil period and the input signal mean period are close (i.e. $T_{m} / T_{\text {soil }}>0.8$ or resonance behaviour).

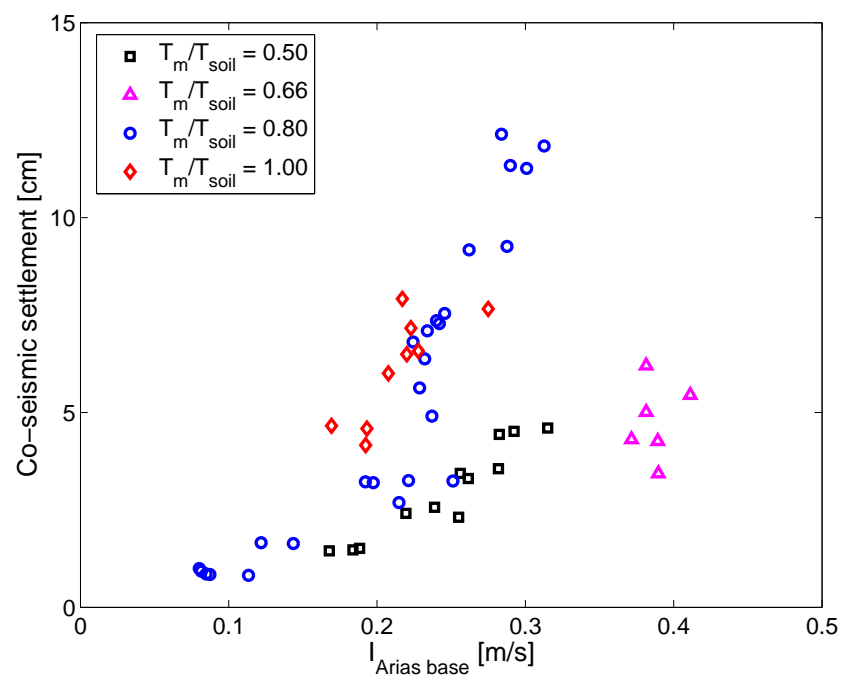

Fig. 23. Comparison of obtained settlement as a function of $I_{\text {Arias }}$ of signal at base foundation in non linear analyses for all cases analysed.

\section{Conclusions}

In the case of large amplitude motion producing liquefaction phenomena in the soil foundation, the structural damage in structures with significant soilstructure interaction effects may be reduced due to the local effects, so, the structure can be considered as a rigid block.

For structures without soil-structure interaction, the response of the structure is principally in flexion mode, thus the structure can present structural damage (i.e. damage in the structural elements due to the large induced deformations) related to the liquefaction phenomena.

Two observations may be noted as far as it concerns the coseismic settlement induced by the liquefaction. Earthquakes with longer $I_{\text {Arias }}$ produce larger coseismic settlement and a higher level of settlement is found when the fundamental soil period and the input signal mean period are close (i.e. resonance behaviour).

According to the comparison of the response obtained in free field condition 
with and without the presence of the structure, two observations may be noted : (i) the pore water pressure distribution at the end of the earthquake motion is modified by the presence of the structure, even if the soil profile is far from it. (ii) the effect of the structure on the response of the free field is not the same and it seems that it depends on both the frequencies of the structure and the input signal.

\section{Acknowledgements}

This study has been done in the framework of the European Community Contract No GRDI-40457, NEMISREF (New methods of mitigation of seismic risk on existing foundations).

\section{References}

[1] D. Aubry, D. Chouvet, A. Modaressi, H. Modaressi, GEFDYN: Logiciel d'Analyse de Comportement Mécanique des Sols par Eléments Finis avec Prise en Compte du Couplage Sol-Eau-Air, Manuel scientifique, Ecole Centrale Paris, LMSS-Mat (1986).

[2] D. Aubry, A. Modaressi, GEFDYN, Manuel scientifique, Ecole Centrale Paris, LMSS-Mat (1996).

[3] A. Arias, A mesure of earthquake intensity, in: Seismic Design for Nuclear Power Plants, R.J. Hansen (ed.), MIT Press, Cambridge, Massachusetts, 1970, pp. 438-483.

[4] H. Modaressi, Modélisation numérique de la propagation des ondes dans les milieux poreux anélastiques, Thèse de doctorat, École Centrale Paris, France (1987).

[5] D. Aubry, H. Modaressi, Seismic wave propagation in soils including non-linear and pore pressure effects, in: Recent Advances in Earthquake Engineering and Structural Dynamics, V. Davidovici (ed.), Ouest Editions, 1992, pp. 209-224.

[6] E. M. Rathje, N. A. Abrahamson, J. D. Bray, Simplified frequency content estimates of earthquake ground motions, Journal of Geotechnical and Geoenvironmental Engineering 124 (2) (1998) 150-159.

[7] D. Aubry, J.-C. Hujeux, F. Lassoudire, Y. Meimon, A double memory model with multiple mechanisms for cyclic soil behaviour, in: Int. Symp. Num. Mod. Geomech, Balkema, 1982, pp. 3-13.

[8] J.-C. Hujeux, Une loi de comportement pour le chargement cyclique des sols, in: Génie Parasismique, V. Davidovici, Presses ENPC, France, 1985, pp. 278-302. 
[9] A. N. Schofield, C. P. Wroth, Critical State Soil Mechanics, McGraw-Hill, London, 1968.

[10] K. H. Roscoe, A. N. Schofield, C. P. Wroth, On the yielding of soils, Géotechnique 8 (1) (1958) 22-52.

[11] M. P. Luong, Phénomènes cycliques dans les sols pulvérulents, Revue Française de Géotechnique 10 (1) (1980) 39-53.

[12] O. C. Zienkiewicz, T. Shiomi, Dynamic behaviour of saturated porous media; the generalised biot formulation and its numerical solution, International Journal for Numerical and Analytical Methods in Geomechanics 8 (1984) 71-96.

[13] O. C. Zienkiewicz, R. L. Taylor, The Finite Element Method, Solid and Fluid Mechanics, Dynamics and Non-linearity, 4th Edition, Vol. 2, McGraw-Hill Book Company, London, 1991.

[14] F. López-Caballero, A. Modaressi, F. Elmi, Identification of an elastoplastic model parameters using laboratory and in-situ tests, in: Deformation Characteristics of Geomaterials, Eds. Di Benedetto et al., A.A. Balkema, ISBN 9058096041, 2003, pp. 1183-1190.

[15] J. A. Santos, A. Gomes Correia, A. Modaressi, F. López-Caballero, R. Carrilho Gomes, Validation of an elastoplastic model to predict secant shear modulus of natural soils by experimental results, in: Deformation Characteristics of Geomaterials, Eds. Di Benedetto et al., A.A. Balkema, ISBN 9058096041, 2003, pp. 1057-1061.

[16] F. Lopez-Caballero, A. Modaressi Farahmand-Razavi, H. Modaressi, Nonlinear numerical method for earthquake site response analysis i- elastoplastic cyclic model \& parameter identification strategy, Bulletin of Earthquake Engineering $5(3)$.

[17] H. B. Seed, R. T. Wong, I. M. Idriss, K. Tokimatsu, Moduli and damping factors for dynamic analyses of cohesionless soils, Journal of Geotechnical Engineering - ASCE 112 (11) (1986) 1016-1032.

[18] H. B. Seed, I. M. Idriss, Ground motion and soil liquefaction during earthquakes., Monograph series, earthquake engineering research institute, University of California, Berkeley, CA. (1982).

[19] S. Koutsourelakis, J. H. Prévost, G. Deodatis, Risk assessment of an interacting structure-soil system due to liquefaction, Earthquake Engineering and Structural Dynamics 31 (4) (2002) 851-879.

[20] R. Popescu, Finite element assessment of the effects of seismic loading rate on soil liquefaction, Canadian Geotechnical Journal 39 (2) (2002) 331-344.

[21] H. B. Seed, I. M. Idriss, Simplified procedure for evaluating soil liquefaction potential, Journal of Soil Mechanics and Foundations Division - ASCE 97 (SM9) (1971) 1249-1273. 
[22] T. L. Youd, I. M. Idriss, R. D. Andrus, I. Arango, G. Castro, J. T. Christian, R. Dobry, W. D. L. Finn, L. F. J. Harder, M. E. Hynes, K. Ishihara, J. P. Koester, S. S. C. Liao, W. F. I. Marcuson, G. Martin, J. K. Mitchell, Y. Moriwaki, M. S. Power, P. K. Robertson, R. B. Seed, K. H. I. Stokoe, Liquefaction resistance of soils: Summary report from the 1996 NCEER and 1998 NCEER/NSF workshops on evaluation of liquefaction resistance of soils, Journal of Geotechnical and Geoenvironmental Engineering - ASCE 127 (10) (2001) 817-833.

[23] I. M. Idriss, Earthquake ground motions at soft soil sites., in: 2nd International Conference on recent Advances in Geotechnical Earthquake Engineering and Soil Dynamics, Vol. 3, St. Louis, Missouri. Eds. Prakash, 1991, pp. 2265-2271.

[24] S. E. Dickenson, R. B. Seed, Non-linear dynamic response of soft and deep cohesive soil deposits, in: Proceedings of the International Workshop on Site Response Subjected to Strong Earthquake Motions, Vol. 2, Yokosuka, Japan, 1996, pp. 67-81.

[25] I. M. Idriss, Response of soft soil sited during earthquakes, in: Proceedings of H. Bolton Seed Memorial Symposium, Vol. 2, J.M. Duncan Ed., BiTech publishers, Vancouver, BC, 1990, pp. 273-289.

[26] B. Ghosh, S. P. G. Madabhushi, Effects of localised soil inhomogenity in modyfyng seismic soil structure interaction, in: 16th ASCE Engineering Mechanics Conference, University of Washington, Seattle, 2003.

[27] M. Zeghal, A. W. Elgamal, Analysis of site liquefaction using earthquake records, Journal of Geotechnical and Geoenvironmental Engineering - ASCE 120 (6) (1994) 996-1017.

[28] K. Tokimatsu, H. Mizuno, M. Kakurai, Building damage associated with geotechnical problems, Soils and Foundations - Special Issue SI (1) (1996) 219234.

[29] S. L. Kramer, A.-W. Elgamal, Modeling soil liquefaction hazards for performance-based earthquake engineering, PEER report 2001/13, College of Engineering University of California, Berkeley (2001).

[30] T. L. Youd, B. Carter, Influence of soil softening and liquefaction on response spectra for bridge design, Utah department of transportation, UT-03.07, Brigham Young University, Provo, Utah (2003).

[31] C. H. Juang, H. Yuan, D. K. Li, S. H. Yang, R. A. Christopher, Estimating severity of liquefaction-induced damage near foundation, Soil Dynamics and Earthquake Engineering 25 (5) (2005) 403-411.

[32] J. F. Bird, J. J. Bommer, H. Crowley, R. Pinho, Modelling liquefaction-induced building damage in earthquake loss estimation, Soil Dynamics and Earthquake Engineering 26 (1) (2006) 15-30.

[33] E. Kausel, J. M. Roesset, J. T. Christian, Nonlinear behavior in soil-structure interaction, Journal of Geotechnical Engineering Division - ASCE 102 (GT12) (1976) 1159-1178. 
[34] R. I. Borja, W. H. Wu, Vibration of foundations on incompressible soils with no elastic region, Journal of Geotechnical and Geoenvironmental Engineering ASCE 120 (9) (1994) 1570-1592.

[35] P. Chakrabortty, R. Popescu, J. H. Prévost, Tower structures on liquefiable soil excited by random seismic input, in: 9th ASCE Specialty Conference on Probabilistic Mechanics and Structural Reliability, Albuquerque, NM,, 2004.

[36] R. Popescu, J. H. Prévost, G. Deodatis, P. Chakrabortty, Dynamics of nonlinear porous media with applications to soil liquefaction, Soil Dynamics and Earthquake Engineering 26 (6-7) (2006) 648-665.

[37] S. P. G. Madabhushi, Response of tower structures to earthquake pertubations, PhD thesis, University of Cambridge (1991).

[38] S. P. G. Madabhushi, A. N. Schofield, Centrifuge modeling of tower structures on saturated sands subjected to earthquake perturbations, Géotechnique 43 (4) (1993) 555-565. 